\title{
Depression symptoms as mediators of inequalities in self- reported health: the case of Southern European elderly
}

\author{
T. Leão ${ }^{1}$, J. Perelman ${ }^{1,2}$ \\ ${ }^{1}$ Escola Nacional de Saúde Pública, Universidade NOVA de Lisboa, 1600-560 Lisboa, Portugal \\ ${ }^{2}$ Centro de Investigação em Saúde Pública, 1600-560 Lisboa, Portugal \\ Address correspondence to T. Leão, E-mail: ti.leao@ensp.unl.pt
}

\begin{abstract}
Background Inequalities in the distribution of self-reported health (SRH) have been widely reported. Its higher expressivity among women, elderly and least educated groups has been partly attributed to differences in their health perceptions. However, this subjectivity may be masking the burden of mental illness in these groups. Thus, we sought to understand if depression symptoms mediate inequalities in SRH.

Methods SHARE waves 4 and 6 , pertaining to Spain, Italy and Portugal, were used $\left(n_{2011}=8517, n_{2015}=11\right.$ 046). Inequalities in SRH were calculated, comparing the risk amongst education level, gender and age groups, adjusting for chronic diseases, functional limitations and country fixed effects. We then tested depression symptoms as mediators.

Results Depression symptoms were associated with poor SRH (odds ratio $(\mathrm{OR})_{2011}=1.379, \mathrm{OR}_{2015}=1.384, P<0.001$ ). Their inclusion reduced the magnitude of the association between SRH and education, annulled the statistical significance for age, and reversed the gender effect. As expected, chronic diseases and functional limitations remained significant predictors of poor SRH.

Conclusions Depression symptoms, together with chronic diseases and functional limitations, explain the poorer SRH of the least educated, female and older groups in the Southern European population. Therefore, tackling inequalities in SRH must require focusing on mental health issues, which disproportionately affect the most vulnerable groups.
\end{abstract}

Keywords gender, mental health, socioeconomics factors

\section{Introduction}

Self-reported health (SRH) has been widely used as a proxy for the health status of populations, and its distribution. ${ }^{1-3}$ Indeed, large discrepancies have been found in SRH according to gender, age and educational subgroups. ${ }^{1-3}$ Overall, in the 28 European countries, poor SRH is mostly concentrated amongst women, with a 2 percentage point gender gap, and amongst the elderly, who experience a more than 10 percentage point higher prevalence than young adults. ${ }^{4}$ The least educated groups have up to $35 \%$ higher prevalence of poor $\mathrm{SRH}$, compared with highly educated ones, ${ }^{2}$ and these educational inequalities persist in older groups: men and women over 60 years old from least educated groups have 2.18 and 2.54 higher risk, respectively, of having poor SRH, compared to those with the highest educational levels. ${ }^{5}$

Objective and subjective arguments have often been raised to explain these distribution patterns. On the one hand, the higher report of poor SRH has been explained by objective reasons, such as the higher prevalence of chronic diseases in these groups ${ }^{6-10}$ _ indeed, SRH has a strong capacity to predict functional decline and mortality. ${ }^{11,12}$ On the other hand, it is often claimed that women, elderly and least educated people tend to be more pessimistic, less able to adapt, and thus more prone to report poor SRH. ${ }^{13}$ This can be intensified by the cultural context that may induce populations, and specifically these groups, to have a less realistic and more negative perception of their health. ${ }^{13}$ This may be the case of Southern and Eastern populations, who have the highest prevalence rates of poor $\mathrm{SRH}^{4}$, and the largest gender and educational gaps in Europe. ${ }^{2,4}$

T. Leão, Researcher

J. Perelman, Assistant Professor 
It is also true that these subjective characteristics may be masking the burden of mental illness. Some authors raise the hypothesis that women, the elderly and least educated people are inflicted by a higher burden of depression and anxiety. $8,14-17$ These symptoms can lead, first, to a worse perception and rating of their own health, ${ }^{8,18}$ and second, to the lower capacity of acceptance and coping with other chronic diseases, amplifying its burden. ${ }^{19-21}$ The differences in the distribution of psychological distress across socioeconomic groups can mediate inequalities in poor SRH amongst gender, age and education groups by creating (i) a poorer perception of SRH by itself and (ii) a worse perception of the burden of the existing chronic diseases or functional limitations.

Regarding the disproportionate rates of, and inequalities in, poor SRH in the Southern European countries, ${ }^{1-6}$ we seek to understand if depression symptoms mediate the association of gender, age and educational level with poor $\mathrm{SRH}$, and if this mediation is explained by the amplifier effect of depression symptoms on chronic diseases and functional limitations.

\section{Methods}

\section{Data source}

We used cross-sectional data from the Survey of Health, Ageing and Retirement in Europe (SHARE). ${ }^{22}$ This is a large database on health, socioeconomic status and social networks, representative for the population over 50 years old, from several European countries. ${ }^{22}$ In order to study the mediator effect of depression symptoms in SRH inequalities in South European countries, we selected data from residents of Spain, Italy and Portugal, collected in waves 4 (2011) and 6 (2015) of this survey. This selection allowed us not only to study the countries where poor SRH prevalence and inequalities are higher, but also to select populations with comparable distributions across educational levels: in these countries, around $60 \%$ of the population over 55 years old have less than lower secondary education $(61.1 \%$ in Italy, $66.7 \%$ in Spain and $80.7 \%$ in Portugal), which differs dramatically from the European mean (37.4\%), and from other European regions. ${ }^{4}$ Observations without information on health, education level, number of chronic diseases, depression symptoms and functional limitations were excluded (from the total 9134 observations, 617 were excluded, i.e. $6.76 \%$ ). We obtained a total number of 8517 observations in 2011 and 11046 in 2015.

\section{Outcome}

The dependent variable was SRH. This variable has been used in several studies of health inequalities. ${ }^{2,9}$ The five categories - excellent, very good, good, fair and poor-were grouped into a binary variable, with ' 1 ' for the poor category, and ' 0 ' for fair or better health status.

\section{Predictors}

The independent variables were education level, gender and age. Education was categorized into four groups: no education, primary, secondary and tertiary education. This variable is widely used to study health inequalities since it is less prone to reverse causation, it has high response rates, and is less subject to response and underreport bias. ${ }^{2,5,23}$ Age was categorized into three groups: 50-64 years old, 65-79 years old and older than 80 .

\section{Mediator}

Depression symptoms were assessed through the EURO-D, a depression scale for use in older people. ${ }^{24,25}$ It ranges from 0 , not depressed, to 12 , very depressed, ${ }^{15,17,24,26}$ depending on the number of depression symptoms selected as present currently or in the last month (depressed mood, pessimism, suicidality, guilt, irritability, fatigue, tearfulness and lack of sleep, interest, appetite, concentration or enjoyment). This variable was used as a continuous variable in the main analysis. For robustness check, it was transformed into four categories: no depression symptoms, 1-2 depression symptoms, 3-5 depression symptoms and more than 6 depression symptoms.

\section{Covariates}

Chronic diseases and functional limitations were considered covariates because they are related to both SRH and education. ${ }^{2,9,23}$ Previously diagnosed antecedents, as heart infarction, hypertension, hypercholesterolemia, cerebral vascular disease, diabetes, chronic lung disease, arthritis/rheumatism, cancer, stomach/duodenal ulcer, Parkinson disease, cataracts and hip or femoral fracture were selected by the respondent and combined into the variable number of chronic diseases. $^{22}$ The Activities of Daily Living index assesses functional limitations. It comprises the tasks of dressing, bathing or showering, eating or cutting up food, walking, and getting in or out of bed, ${ }^{22}$ and its score (from 0 to 5 ) reflects the number of those that the respondent had difficulties to perform. Both covariates were used as continuous variables. Country was also included in the models as a fixed effect, since its characteristics (observable or unobservable) may influence all of the previously described variables. ${ }^{27}$

\section{Data analysis}

We described the distribution by gender, age groups and education level, and compared the distribution of poor SRH and depression symptoms among these groups. 
Health inequalities were calculated using multivariate logistic regressions. First, we compared the odds of having poor SRH between education groups, females and older age groups, controlling for country fixed effects. Second, we added chronic diseases and functional limitations to the previous model, in order to control for physical conditions. Third, we added depression symptoms to the model and, finally, to understand if depression symptoms were amplifiers of the burden of chronic diseases and functional limitations, we included the interaction of depression symptoms with chronic diseases and with functional limitations. We then stratified the analyses by gender, and for robustness check we repeated the analysis using depression symptoms as a categorical variable. Population weights ${ }^{22}$ were used throughout all these steps.

\section{Results}

In 2011, about 1 in 10 respondents reported poor SRH, and more than half of the respondents had primary education or less (Table 1). A very large proportion of the sample $(80.16 \%)$ had one depression symptom or more, $75.05 \%$ had at least one chronic disease, and only $11.34 \%$ had no functional limitations. Females, older and least educated groups had higher prevalence rates of poor SRH and a higher number of depression symptoms (Fig. 1). The 2015 sample followed a similar distribution.

In model 1, we observed that persons with lower education levels had a greater probability of having poor SRH compared to those with tertiary education (odds ratio $(\mathrm{OR})_{2011}=1.759$ and $\mathrm{OR}_{2015}=1.621, P<0.05$ for secondary education, $\mathrm{OR}_{2011}=3.408$ and $\mathrm{OR}_{2015}=3.005, P<$ 0.001 for primary education, and $\mathrm{OR}_{2011}=6.080$ and $\mathrm{OR}_{2015}=4.179$ for no education levels, $\left.P<0.001\right)$ (Table 2). Women and older people were significantly more likely to suffer from poor SRH $\left(\mathrm{OR}_{2011}=1.564\right.$, $P<0.001$ and $\mathrm{OR}_{2015}=1.469, P<0.01$ for females, $\mathrm{OR}_{2011}=2.043$ and $\mathrm{OR}_{2015}=1.504$ for 65-79 years old, and $\mathrm{OR}_{2011}=3.626$ and $\mathrm{OR}_{2015}=2.835$ for over 80 years old groups, $P<0.001$ ).

In both samples, after adjusting for chronic diseases and functional limitations (model 2), the protective effect of education lost some magnitude. The gender effect became weaker, as did the effect of age. Even so, the effect of education, gender, and age remained statistically significant for a $95 \%$ confidence interval (CI) in 2011, losing its significance for gender and for the 65-79 years age group in 2015 .

The inclusion of depression symptoms in the model (model 3) not only showed a statistically significant association $\left(\mathrm{OR}_{2011}=1.379\right.$ and $\left.\mathrm{OR}_{2015}=1.384, P<0.001\right)$, but
Table 1 Characterization of the population. Population aged 50 years old or more

\begin{tabular}{|c|c|c|}
\hline & $\begin{array}{l}\text { Wave 4-2011 } \\
\text { Number }\end{array}$ & $\begin{array}{l}\text { Wave 6-2015 } \\
\text { Number }\end{array}$ \\
\hline Sample size $(n)$ & 8517 & 11046 \\
\hline \multicolumn{3}{|l|}{ Education level } \\
\hline No education & $730(8.6 \%)$ & $1426(12.9 \%)$ \\
\hline Primary & $4104(48.2 \%)$ & $4310(39.0 \%)$ \\
\hline Secondary & $2973(34.9 \%)$ & $4232(38.3 \%)$ \\
\hline Tertiary & $710(8.3 \%)$ & $1078(9.8 \%)$ \\
\hline \multicolumn{3}{|l|}{ Gender } \\
\hline Male & $3853(45.2 \%)$ & $4992(45.2 \%)$ \\
\hline Female & $4664(54.8 \%)$ & $6054(54.8 \%)$ \\
\hline \multicolumn{3}{|l|}{ Age groups } \\
\hline $50-64$ & $4001(47.0 \%)$ & $4598(41.6 \%)$ \\
\hline $65-79$ & $3575(42.0 \%)$ & 4998 (45.2\%) \\
\hline 80 and over & $941(11.0 \%)$ & $1450(13.1 \%)$ \\
\hline \multicolumn{3}{|l|}{$\mathrm{SRH}$} \\
\hline Fair or good & $7334(86.1 \%)$ & $9921(89.8 \%)$ \\
\hline Poor & $1183(13.9 \%)$ & $1125(10.2 \%)$ \\
\hline Chronic diseases [mean \pm SD] & $1.81 \pm 1.54$ & $1.78 \pm 1.61$ \\
\hline Functional limitations [mean \pm SD] & $0.30 \pm 0.01$ & $0.21 \pm 0.79$ \\
\hline Depression symptoms [mean \pm SD] & $2.92 \pm 2.56$ & $2.70 \pm 2.60$ \\
\hline
\end{tabular}

SD, standard deviation.

also attenuated the effect of education, and removed the statistical significance of the remaining gender and age groups. The interaction of depression symptoms with chronic diseases (model 4) showed a slight protector effect $\left(\mathrm{OR}_{2011}=0.959, \mathrm{OR}_{2015}=0.963, P<0.001\right)$ but did not substantially alter the above mentioned results. The interaction of depression symptoms with functional limitations (model 5) was not statistically significant in any of the samples.

Results from the 2015 wave essentially confirmed previous ones. Note, however, that the association with gender now reversed, with female gender being protective of poor $\mathrm{SRH}$ when adjusting for depression symptoms. The association between SRH and chronic disease and functional limitations also lost some of its magnitude but did not lose statistical significance.

The stratification by gender (Supplementary Table S1) overall supported the previous results: depression symptoms partially explained the effect of education on SRH in males, and fully in females, and the interaction between chronic diseases and depression symptoms had a small protector effect for poor SRH. The robustness check (Supplementary Table S2) confirmed the above-mentioned results. 


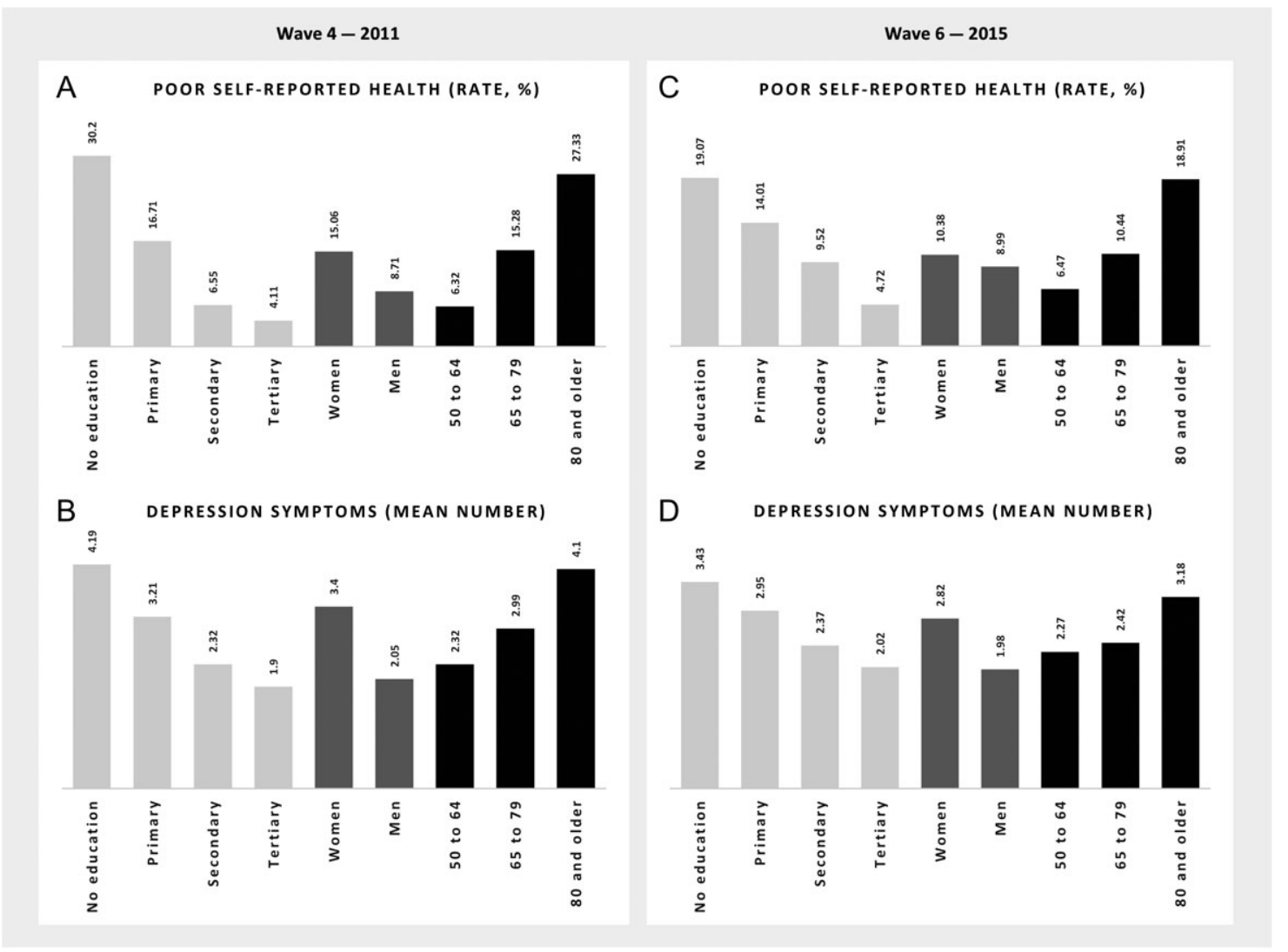

Fig. 1 Distribution of poor SRH (A and C) and depression symptoms ( $B$ and D) by education, gender, and age groups, in wave 4 and 6 samples.

\section{Discussion}

\section{Main finding of this study}

Women, older and least educated individuals were more prone to poor SRH. Depression symptoms had a strong mediator effect between sociodemographic factors and SHR. The interaction of chronic diseases and depression symptoms showed a small but significant protective effect.

\section{What is already known on this topic}

It had been widely reported that the elderly, females, and least educated groups tend to have a higher burden of mental illness ${ }^{8,14-18}$ and report poorer SRH. ${ }^{1,3}$ These groups tend to have less differentiated jobs, characterized by their high strain and low autonomy, and lower incomes, which leads to worse working and living conditions, being exposed to higher levels of stress, anxiety and marginalization. Together with their lower health literacy, these factors contribute to a higher risk of developing depression symptoms and, in consequence, to mediate between socioeconomic inequalities and the worst self-perceived and SRH status. ${ }^{7,28,29}$

\section{What this study adds}

This study shows that education inequalities are explained not only by chronic diseases and functional limitations, but the unequal distribution of depression symptoms plays a major role in accounting for these inequalities. This is in line with the evidence that poorly educated groups tend to have a higher burden of physical ${ }^{6-8}$ and psychological conditions, ${ }^{30,31}$ and suffer from higher mortality rates. ${ }^{5,7,10}$ It also supports the evidence that poor SRH is strongly associated with chronic diseases and, to a larger extent, with depression. ${ }^{32,33}$

This study also shows that these conditions not only explain the higher rates of poor SRH reported by older individuals and females, but even reverse the gender effect on SRH. This helps to understand the classic result that women tend to report poorer health than men; ${ }^{14}$ it shows that if women did not have a higher burden of depression symptoms, they would report even lower rates of poor SRH than men. The small protective effect of female gender is in line with findings discussed by Macintyre et al: ${ }^{34}$ there are small gender differences in reporting pain and other symptoms when controlling for the underlying medical conditions, and these tend to be overexpressed by men. 
Table 2 Association between education level, gender, age and poor SRH, progressively adjusted for chronic diseases, functional limitations, depression symptoms, and interaction between depression symptoms, chronic diseases and functional limitations

\begin{tabular}{|c|c|c|c|c|c|c|c|c|}
\hline & \multicolumn{4}{|l|}{ Wave 4-2011 } & \multicolumn{4}{|l|}{ Wave 6-2015 } \\
\hline & $\begin{array}{l}\text { Model } 1 \\
\text { OR (95\% CI) }\end{array}$ & $\begin{array}{l}\text { Model } 2 \\
\text { OR (95\% Cl) }\end{array}$ & $\begin{array}{l}\text { Model } 3 \\
\text { OR (95\% Cl) }\end{array}$ & $\begin{array}{l}\text { Model } 4 \\
\text { OR }(95 \% \text { Cl) }\end{array}$ & $\begin{array}{l}\text { Model } 1 \\
\text { OR (95\% Cl) }\end{array}$ & $\begin{array}{l}\text { Model } 2 \\
\text { OR (95\% Cl) }\end{array}$ & $\begin{array}{l}\text { Model } 3 \\
\text { OR }(95 \% \text { Cl) }\end{array}$ & $\begin{array}{l}\text { Model } 4 \\
\text { OR }(95 \% \text { Cl) }\end{array}$ \\
\hline \multicolumn{9}{|l|}{ Education (Ref.: tertiary) } \\
\hline Secondary & $\begin{array}{l}1.759^{*} \\
(1.005-3.081)\end{array}$ & $\begin{array}{l}1.646 \\
(0.947-2.859)\end{array}$ & $\begin{array}{l}1.374 \\
(0.743-2.541)\end{array}$ & $\begin{array}{l}1.384 \\
(0.737-2.598)\end{array}$ & $\begin{array}{l}1.621^{*} \\
(1.013-2.595)\end{array}$ & $\begin{array}{l}1.355 \\
(0.831-2.210)\end{array}$ & $\begin{array}{l}1.128 \\
(0.681-1.868)\end{array}$ & $\begin{array}{l}1.097 \\
(0.662-1.819)\end{array}$ \\
\hline Primary & $\begin{array}{l}3.408 * * * \\
(1.957-5.934)\end{array}$ & $\begin{array}{l}2.427 * * \\
(1.404-4.193)\end{array}$ & $\begin{array}{l}1.980 * \\
(1.076-3.644)\end{array}$ & $\begin{array}{l}1.959 * \\
(1.047-3.664)\end{array}$ & $\begin{array}{l}3.005^{\star * *} \\
(1.882-4.798)\end{array}$ & $\begin{array}{l}1.953 * * \\
(1.187-3.213)\end{array}$ & $\begin{array}{l}1.506 \\
(0.902-2.515)\end{array}$ & $\begin{array}{l}1.437 \\
(0.862-2.397)\end{array}$ \\
\hline No education & $\begin{array}{l}6.080 * * * \\
(3.366-10.982)\end{array}$ & $\begin{array}{l}3.500 * * * \\
(1.900-6.448)\end{array}$ & $\begin{array}{l}2.553 * * \\
(1.304-4.997)\end{array}$ & $\begin{array}{l}2.522 * * \\
(1.273-4.995)\end{array}$ & $\begin{array}{l}4.179 * * * \\
(2.567-6.801)\end{array}$ & $\begin{array}{l}2.461 * * \\
(1.426-4.248)\end{array}$ & $\begin{array}{l}1.730 \\
(0.970-3.087)\end{array}$ & $\begin{array}{l}1.649 \\
(0.922-2.951)\end{array}$ \\
\hline \multicolumn{9}{|l|}{ Gender (Ref.: male) } \\
\hline Female & $\begin{array}{l}1.564^{* * *} \\
(1.311-1.865)\end{array}$ & $\begin{array}{l}1.284^{*} \\
(1.056-1.561)\end{array}$ & $\begin{array}{l}0.827 \\
(0.667-1.027)\end{array}$ & $\begin{array}{l}0.833 \\
(0.672-1.033)\end{array}$ & $\begin{array}{l}1.469 * * \\
(1.173-1.840)\end{array}$ & $\begin{array}{l}1.121 \\
(0.870-1.444)\end{array}$ & $\begin{array}{l}0.745^{*} \\
(0.570-0.973)\end{array}$ & $\begin{array}{l}0.747^{*} \\
(0.573-0.974)\end{array}$ \\
\hline \multicolumn{9}{|l|}{ Age (Ref.: 50-64) } \\
\hline $65-79$ & $\begin{array}{l}2.043^{* * *} \\
(1.662-2.511)\end{array}$ & $\begin{array}{l}1.240 \\
(0.988-1.557)\end{array}$ & $\begin{array}{l}1.292^{*} \\
(1.024-1.631)\end{array}$ & $\begin{array}{l}1.250 \\
(0.991-1.576)\end{array}$ & $\begin{array}{l}1.504^{* * *} \\
(1.135-1.992)\end{array}$ & $\begin{array}{l}0.858 \\
(0.630-1.169)\end{array}$ & $\begin{array}{l}0.854 \\
(0.611-1.195)\end{array}$ & $\begin{array}{l}0.858 \\
(0.613-1.196)\end{array}$ \\
\hline 80 and over & $\begin{array}{l}3.626^{\star * \star} \\
(2.802-4.693)\end{array}$ & $\begin{array}{l}1.407^{*} \\
(1.026-1.930)\end{array}$ & $\begin{array}{l}1.275 \\
(0.914-1.779)\end{array}$ & $\begin{array}{l}1.240 \\
(0.891-1.724)\end{array}$ & $\begin{array}{l}2.835^{* * *} \\
(2.052-3.915)\end{array}$ & $\begin{array}{l}1.187^{\star *} \\
(0.818-1.723)\end{array}$ & $\begin{array}{l}1.098 \\
(0.741-1.628)\end{array}$ & $\begin{array}{l}1.187 \\
(0.751-1.639)\end{array}$ \\
\hline \multicolumn{9}{|l|}{ Country (Ref.: Spain) } \\
\hline Italy & $\begin{array}{l}0.943 \\
(0.783-1.135)\end{array}$ & $\begin{array}{l}1.100 \\
(0.895-1.352)\end{array}$ & $\begin{array}{l}1.118 \\
(0.903-1.382)\end{array}$ & $\begin{array}{l}1.113 \\
(0.901-1.374)\end{array}$ & $\begin{array}{l}0.726 * * * \\
(0.577-0.914)\end{array}$ & $\begin{array}{l}0.807^{*} \\
(0.626-1.041)\end{array}$ & $\begin{array}{l}0.641 * * \\
(0.487-0.843)\end{array}$ & $\begin{array}{l}0.639 * * \\
(0.486-0.840)\end{array}$ \\
\hline Portugal & $\begin{array}{l}1.437^{*} \\
(1.053-1.960)\end{array}$ & $\begin{array}{l}1.496^{*} \\
(1.029-2.175)\end{array}$ & $\begin{array}{l}1.414 \\
(0.965-2.073)\end{array}$ & $\begin{array}{l}1.387 \\
(0.947-2.032)\end{array}$ & $\begin{array}{l}1.259 \\
(0.910-1.742)\end{array}$ & $\begin{array}{l}0.777 \\
(0.546-1.106)\end{array}$ & $\begin{array}{l}0.614^{*} \\
(0.420-0.896)\end{array}$ & $\begin{array}{l}0.638^{*} \\
(0.441-0.924)\end{array}$ \\
\hline Chronic disease & & $\begin{array}{l}1.832 * * * \\
(1.717-1.956)\end{array}$ & $\begin{array}{l}1.660 * * * \\
(1.552-1.776)\end{array}$ & $\begin{array}{l}2.013 * * * \\
(1.786-2.269)\end{array}$ & & $\begin{array}{l}1.772 * * * \\
(1.661-1.891)\end{array}$ & $\begin{array}{l}1.607 * * * \\
(1.496-1.725)\end{array}$ & $\begin{array}{l}1.939 * * * \\
(1.708-2.202)\end{array}$ \\
\hline Functional limitations & & $\begin{array}{l}1.663^{* * *} \\
(1.530-1.808)\end{array}$ & $\begin{array}{l}1.486^{* * *} \\
(1.367-1.615)\end{array}$ & $\begin{array}{l}1.457 * * * \\
(1.232-1.723)\end{array}$ & & $\begin{array}{l}1.783 * * * \\
(1.616-1.967)\end{array}$ & $\begin{array}{l}1.553^{* * *} \\
(1.413-1.706)\end{array}$ & $\begin{array}{l}1.407 * * * \\
(1.125-1.759)\end{array}$ \\
\hline Depression symptoms & & & $\begin{array}{l}1.379 * * * \\
(1.325-1.434)\end{array}$ & $\begin{array}{l}1.535^{* * *} \\
(1.433-1.644)\end{array}$ & & & $\begin{array}{l}1.384^{* * *} \\
(1.330-1.440)\end{array}$ & $\begin{array}{l}1.519 * * * \\
(1.410-1.636)\end{array}$ \\
\hline \multicolumn{4}{|c|}{ Interaction (depression symptoms $\times$ chronic disease) } & $\begin{array}{l}0.959 * * * \\
(0.938-0.980)\end{array}$ & & & & $\begin{array}{l}0.963 * * * \\
(0.943-0.983)\end{array}$ \\
\hline \multicolumn{4}{|c|}{ Interaction (depression symptoms $\times$ functional limitations) } & $\begin{array}{l}1.005 \\
(0.977-1.034)\end{array}$ & & & & $\begin{array}{l}1.017 \\
(0.980-1.055)\end{array}$ \\
\hline
\end{tabular}

$P$-values: ${ }^{*} 0.05, * * 0.01, * * * 0.001 ; \mathrm{OR}$, odds ratio; $\mathrm{Cl}$, confidence interval. 
Finally, this study shows that, unlike Moussavi and Chatterji, ${ }^{32}$ the respondents who accumulate depression symptoms and chronic diseases tend to report less poor SRH than those with a smaller burden of these conditions. An explanation may be that depression symptoms are usually overlooked by the individuals and by the healthcare system, except when they coexist with chronic diseases. Individuals tend to undervalue their psychological symptoms, but are prone to seek healthcare for their physical conditions. As depression symptoms tend to exacerbate physical ones, ${ }^{38,39}$ they may lead the individual to search for healthcare, which can increase the diagnosis and treatment of these individuals for physical and psychological conditions. ${ }^{40}$ Also, patients with chronic physical diseases, such as diabetes or hypertension, tend to be more frequently checked by the healthcare services. Thus, since the literature has been continuously raising the issue of the double burden of psychological and physical health conditions, ${ }^{19-21}$ these individuals with chronic diseases may have a better diagnosis and treatment of both physical and psychological conditions, while those with isolated depression symptoms are neglected. The use of self-assessed depression symptoms, instead of using clinically diagnosed depression, as in Moussavi and Chatterji, ${ }^{32}$ may have allowed us to capture these undiagnosed depression cases.

\section{Limitations of this study}

We must consider five major limitations in this study. First, we were not able to explore the causal pathway of depression symptoms into poor SRH, because we did not use longitudinal data; still, the use of cross-sectional analyses, repeated to check for consistency, and with different stages of controlling for different factors (the four multivariate models) was adequate to test how depression symptoms mediate the relationship between gender, education, age and poor $\mathrm{SRH}^{41}$ which was the aim of the study.

Second, we assessed the number of chronic diseases, functional limitations, and depression symptoms using selfreported scales, which can be susceptible to bias. However, these are widely used scales ${ }^{3,18,24}$ that rely on dichotomous presence/absence of specific symptoms or medically diagnosed conditions, ${ }^{22}$ so that the risk of reporting bias is low. Indeed, the number of chronic diseases was assessed through selecting and counting from a list of specific conditions that were previously diagnosed by a doctor (heart attack, stroke, hypertension, hypercholesterolemia, diabetes, cancer, etc.). ${ }^{22}$ Functional limitations were accessed by a commonly used clinical index (the Activities Daily Living
Index) that sums, from a list of five tasks (dressing, bathing or showering, eating, cutting up food, walking across a room and getting in or out of bed), how many the respondent has difficulties to perform. ${ }^{22}$ The same occurs with the Euro-D Scale, which is composed of 12 items (depressed mood, pessimism, suicidality, guilt, sleep, interest, irritability, appetite, fatigue, concentration, enjoyment and tearfulness) with dichotomous presence/absence answers, which are coincident with the DSM-5 criteria and strongly correlated with the Geriatric Mental Scale. ${ }^{24,25}$

Third, we used depression symptoms as a proxy for depression. Because, some of these symptoms can also be present in other physical and psychological disorders (such as anxiety disorders, hyper and hypothyroidism, dementia, or drug abuse, amongst others), there may be a confounding effect from these unobserved conditions. However, the EURO-D scale has been widely used in the literature and has shown good specificity and sensitivity for predicting depression amongst the elderly. ${ }^{15,24-26}$

Fourth, we used the OR as a measure of risk. Though the relative and slope index of inequalities and concentration curves reflect in one measure the relative dimensions of each strata and the health distribution in them, ${ }^{42}$ we favoured the $\mathrm{OR}$ as it was more adequate to test the mediator effect of depression symptoms on SRH, while revealing the weights of each covariate.

Finally, the findings about gender differences cannot be generalized; we were not able to adjust our models for all chronic diseases or other mental health disorders, and some of those tend to have a higher burden of disease in older men than women (as sequelae from unintentional injuries, ${ }^{35,36} \mathrm{HIV}$, tuberculosis, hepatitis, ${ }^{36}$ alcoholism, schizophrenia, ${ }^{34,36,37}$ amongst others).

In conclusion, this study enlightens the importance of depression symptoms, together with chronic diseases and functional limitations, as major drivers of gender, age and education-related inequalities in SRH. Stated differently, our study shows that if female, older and least educated groups did not have depression symptoms, they would not perceive or report as frequently their health status as poor. Thus, this study reinforces that mental health is not only a leading cause of loss of healthy life years in Southern Europe (fourth cause in Portugal, fifth in Spain and seventh in Italy), ${ }^{36}$ but also a decisive barrier that needs to be overcome in order to reduce health inequalities in these populations.

\section{Supplementary data}

Supplementary data are available at the Journal of Public Health online. 


\section{Acknowledgements}

We are grateful to Miguel Cabral and Jorge Rodrigues for all their comments in this work. Although this paper is unrelated to the project, T.L. performed this study while financed by the SILNE-R project, funded by the European's Union Horizon 2020 research and innovation programme (Grant agreement number 635056), which we acknowledge. Moreover, this paper uses data from SHARE Waves 4 and 6 (DOIs: 10.6103/ SHARE.w4.600 and 10.6103/SHARE.w6.600), see BörschSupan et al. (2013) for methodological details. The SHARE data collection has been primarily funded by the European Commission through FP5 (QLK6-CT-2001-00360), FP6 (SHARE-I3: RII-CT-2006-062193, COMPARE: CIT5-CT2005-028857, SHARELIFE: CIT4-CT-2006-028812) and FP7 (SHARE-PREP: No211909, SHARE-LEAP: $\quad \mathrm{N}^{\circ} 227822$, SHARE M4: $\mathrm{N}^{\circ}$ 261982). Additional funding from the German Ministry of Education and Research, the U.S. National Institute on Aging (U01_AG09740-13S2, P01_AG005842, P01_AG08291, P30_AG12815, R21_AG025169, Y1-AG4553-01, IAG_BSR06-11, OGHA_04-064) and from various national funding sources is gratefully acknowledged (see www. share-project.org).

\section{References}

1 Eikemo TA, Bambra $\mathrm{C}$, Judge $\mathrm{K}$ et al. Welfare state regimes and differences in self-perceived health in Europe: a multilevel analysis. Soc Sci Med [Internet] 2008;66(11):2281-95. http://linkinghub.elsevier. $\mathrm{com} /$ retrieve/pii/S027795360800049X.

$2 \mathrm{Hu} \mathrm{Y}$, van Lenthe FJ, Borsboom GJ et al. Trends in socioeconomic inequalities in self-assessed health in 17 European countries between 1990 and 2010. J Epidemiol Community Health [Internet] 2016;70(7): 644-52. http://jech.bmj.com/lookup/doi/10.1136/jech-2015-206780.

3 Subramanian SV, Huijts T, Avendano M. Self-reported health assessments in the 2002 World Health Survey: how do they correlate with education? Bull World Health Organ 2010;88(2):131-8.

4 Eurostat. Eurostat Population Data [Internet]. [cited 2017 Jan 19]. http://ec.europa.eu/eurostat/web/population-demography-migrationprojections/population-data/main-tables

5 Huisman M, Kunst AE, Mackenbach JP. Socioeconomic inequalities in morbidity among the elderly; a European overview. Soc Sci Med [Internet] 2003;57(5):861-73. http://linkinghub.elsevier.com/retrieve/ pii/S0277953602004549.

6 Huisman M, Kunst AE, Bopp M et al. Educational inequalities in cause-specific mortality in middle-aged and older men and women in eight western European populations. Lancet 2005;365(9458):493-500.

7 Marmot M, Atkinson T. Fair Society, Healthy Lives. London; 2010.

8 Malmusi D, Artazcoz L, Benach J et al. Perception or real illness? How chronic conditions contribute to gender inequalities in selfrated health. Eur J Public Health 2012;22(6):781-6.
9 Mackenbach J, Stirbu I, Roskam A et al. Socioeconomic inequalities in health in 22 European countries. N Engl J Med 2008;358(23): 2468-81.

10 Mackenbach JP. Health Inequalities: Europe in Profile [Internet]. London: European Commission, 2006. http://www.who.int/social_ determinants/resources/european_inequalities.pdf.

11 Grant MD, Piotrowski ZH, Chappell R. Self-reported health and survival in the longitudinal study of aging, 1984-1986. J Clin Epidemiol 1995;48(3):375-87.

12 Kunst AE, Geurts JJM, van den Berg J. International variation in socioeconomic inequalities in self reported health. I Epidemiol Community Heal 1995;49:117-23.

13 Zajacova A, Dowd JB. Reliability of self-rated health in US adults. Am J Epidemiol 2011;174(8):977-83.

14 Perelman J, Fernandes A, Mateus C. Gender disparities in health and healthcare: results from the Portuguese National Health Interview Survey. Cad Saude Publica [Internet] 2012;28(12):2339-48. http://www.ncbi.nlm.nih.gov/pubmed/23288066.

15 Prince MJ, Beekman ATF, Deeg DJH et al. Depression symptoms in late life assessed during the EURO-D scale. Effect of age, gender and marital status in 14 European centres. Br J Psychiatry 1999;174: 339-45.

16 Lorant V. Socioeconomic inequalities in depression: a meta-analysis. Am J Epidemiol [Internet] 2003;157(2):98-112. http://aje.oupjournals. org/cgi/doi/10.1093/aje/kwf182.

17 Copeland JRM, Beekman ATF, Braam AW et al. Depression among older people in Europe: the EURODEP studies. World Psychiatry Internet] 2004;3(1):45-9. http://www.ncbi.nlm.nih.gov/pubmed/ 16633454\%5Cnhttp:/ /www.pubmedcentral.nih.gov/articlerender. fcgi? artid=PMC1414664.

18 Molarius A, Janson S. Self-rated health, chronic diseases, and symptoms among middle-aged and elderly men and women. J Clin Epidemiol 2002;55(4):364-70.

19 Ho CS, Feng L, Fam J et al. Coexisting medical comorbidity and depression: multiplicative effects on health outcomes in older adults. Int Psychogeriatrics 2014;26(7):1221-9.

20 Panagioti M, Scott C, Blakemore A et al. Overview of the prevalence, impact, and management of depression and anxiety in chronic obstructive pulmonary disease. Int J Chron Obs Pulmon Dis 2014;9: 1289-1306.

21 Ormel J, Kempen GIJM, Deeg PDJH et al. Functioning, well-being, and health perception in late middle-aged and older people: comparing the effects of depressive symptoms and chronic medical conditions. I Am Geriatr Soc 1998;46:39-48.

22 Börsch-Supan A. Survey of Health, Ageing and Retirement in Europe (SHARE) Wave 4. Release version: 5.0.0. SHARE-ERIC. Data set DOI 106103/SHARE.w4500. 2016.

23 Meara ER, Richards S, Cutler DM. The gap gets bigger: changes in mortality and life expectancy, by education, 1981-2000. Health Aff 2008;27(2):350-60.

24 Guerra M, Ferri C, Llibre J et al. Psychometric properties of EURO-D, a geriatric depression scale: a cross-cultural validation study. BMC Psychiatry [Internet] 2015;15(1):12. http://www.biomedcentral. com/1471-244X/15/12. 
25 Prince MJ, Reischies F, Beekman ATF et al. Development of the EURO-D scale-a European Union initiative to compare symptoms of depression in 14 European centres. Br J Psycbiatry 1999;174 (APR.):330-8.

26 Copeland JRM, Prince M, Wilson KCM et al. The Geriatric Mental State Examination in the 21st century. Int J Geriatr Psychiatry 2002;17 (8):729-32.

27 Torres-Reyna O. Panel Data Analysis Fixed and Random Effects [Internet]. 2007. http://dss.princeton.edu/training/Panel101.pdf

28 Mackenbach JP. The persistence of health inequalities in modern welfare states: the explanation of a paradox. Soc Sci Med [Internet] 2012;75 (4):761-9. http://dx.doi.org/10.1016/j.socscimed.2012.02.031

29 Whitehead M. The concepts and principles of equity and health. Health Promot Int [nternet] 1991;6(3):217-28. http://joh.sagepub. com/content $/ 22 / 3 / 429$.short.

30 Lobo A, Saz P, Marcos G et al. The prevalence of dementia and depression in the elderly community in a Southern European Population. The Zaragoza Study. Arch Gen Psychiatry 1995;52(6):497-506.

31 Weyerer S, Eifflaender-Gorfer S, Köhler L et al. Prevalence and risk factors for depression in non-demented primary care attenders aged 75 years and older. J Affect Disord [Internet] 2008;111(2-3):153-63. http://dx.doi.org/10.1016/j.jad.2008.02.008

32 Moussavi S, Chatterji S. Depression, chronic diseases, and decrements in health: results from the World Health Surveys. Lancet 2007;370:851-8.

33 Chang-Quan H, Xue-Mei Z, Bi-Rong D et al. Health status and risk for depression among the elderly: a meta-analysis of published literature. Age and Ageing [Internet] 2010;39(1):23-30. http://www.ncbi. nlm.nih.gov/pubmed/19903775.
34 Macintyre S, Hunt K, Sweeting H. Gender differences in health: are things really as simple as they seem? Soc Sci Med 1996;42(4):617-24.

35 Vos T, Barber RM, Bell B et al. Global, regional, and national incidence, prevalence, and years lived with disability for 301 acute and chronic diseases and injuries in 188 countries, 1990-2013: a systematic analysis for the Global Burden of Disease Study 2013. Lancet [Internet] 2015;386(9995):743-800. http://dx.doi.org/10.1016/ S0140-6736(15)60692-4

36 Institute for Health Metrics and Evaluation. Data Visualization [Internet]. 2015 [cited 2015 Dec 27]. http://www.healthdata.org/ results/data-visualizations

37 Rosenfield S, Mouzon D. Handbook of the sociology of mental health [Internet]. In: Aneshensel CS, Phelan JC, Bierman A (eds). Handbook of the Sociology of Mental Health. Dordrecht: Springer, 2013: 277-96. http://link.springer.com/10.1007/978-94-007-4276-5.

38 Katon WJ. Clinical and health services relationships between major depression, depressive symptoms, and general medical illness. Biol Psychiatry 2003;54(3):216-26.

39 Von Korff M, Simon G. The relationship between pain and depression. Br J Psycbiatry 1996;168(June Suppl. 30):101-8.

40 Egede LE, Zheng D, Simpson K. Comorbid depression is associated with increased health care use and expenditures in individuals with diabetes. Diabetes Care 2002;25(3):464-70.

41 Richiardi L, Bellocco R, Zugna D. Mediation analysis in epidemiology: methods, interpretation and bias. Int J Epidemiol 2013;42(5):1511-9.

42 Mackenbach JP, Kunst AE. Measuring the magnitude of socioeconomic inequalities in health: an overview of available measures illustrated with two examples from Europe. Soc Sci Med 1997;44(6): 757-71. 